\title{
AVALIAÇÃO DO MEIO "AGAR XILOSE LISINA VERDE BRILHANTE" NO ISOLAMENTO DE SALMONELLA
}

\author{
Deise Pasetto Falcão* \\ Italo Suassuna** \\ Ivone Rocco Suassuna ***
}

RSPUB9/445

Falcão, D. P. et al. Avaliação do meio "Agar Xilose Lisina Verde Brilhante" no isolamento de Salmonella. Rev. Saúde públ., S. Paulo, 13:43-6, 1979.

Resumo: Ao pesquisar-se a presença de Salmonella a partir de materiais diversos, foram empregados vários meios de cultura e entre eles o meio Agar Xilose Lisina Verde Brilhante, com a finalidade de avaliá-lo em relafáo a outros meios seletivo-indicadores mais comumente empregados no isolamento desses microrganismos. Os resultados mostraram que o meio Agar Xilose Lisina Verde Brilhante foi inferior aos Agar SS e Agar Verde Brilhante, ligeiramente superior ao Agar EMB e superior ao Agar Sulfito de Bismuto no isolamento de Salmonella. Grande vantagem adicional desse meio é que as colônias de Salmonella apresentam-se facilmente identificáveis.

UNITERMOS: Salmonella, isolamento. Meios de cultura.

O isolamento de Salmonella constitui um problema técnico complexo, principalmente quando os germes se apresentam em número reduzido no material a ser examinado. Para conseguir isolamento lança-se mão de meios seletivo-indicadores e de meios de enriquecimento.

Os meios de cultura podem ser mais ou menos inibitórios. Alguns permitem o crescimento de quase todas as enterobactérias, pois muitas vezes algumas espécies somente crescem em ausência de elementos muito inibidores. Entre os meios menos seletivos, que permitem uma verificação mais acurada de toda a flora gram-negativa, encontra-se, por exemplo, o meio Agar EMB. ${ }^{*}$ Outros, entretanto, são altamente seletivos, permitindo o crescimento de um número muito reduzido de germes. Os pesquisadores procuram, cada vez mais, os meios que proporcionem um bom desenvolvimento de salmonelas, mas que, ao mesmo tempo, inibam outras enterobactérias, principalmente Proteus e coliformes. Os proteus sendo germes lactose-negativos poderão ser confundidos, muitas vezes, com as salmonelas, pois em quase todos esses meios, a principal indicação é representada por uma alteração de um carboidrato que quase sempre é a lactose. Os coliformes, prin-

* Da Faculdade de Ciências Farmacêuticas - UNESP - Rua Expedicionários do Brasil, 1621 - Campus de Araraquara - 14800 - Araraquara, SP - Brasil.

* Da Faculdade de Ciências Médicas da Universidade Federal do Estado do Rio de Janeiro - Rua Teodoro da Silva. $48-20000-$ Rio de Janeiro - RJ. Brasil.

*** Do Instituto de Microbiologia da Universidade Federal do Rio de Janeiro - Centro de Ciências da Saúde - 20000 - Rio de Janeiro - RJ. Brasil. 
FALCÃO, D. P. et al. Avaliação do meio "Agar Xilose Lisina Verde Brilhante" no isolamento de Salmonella. Rev. Saúde públ., S. Paulo, 13:43-6, 1979.

cipalmente os pertencentes ao gênero $E s$ cherichia, podem ter marcada ação antibiótica contra muitas salmonelas (Levine e Tanimoto:). Entre os meios altamente inibidores encontramos o Agar SS *, que é uma modificação do meio de desoxicolato- citrato, à base de sais biliares. Esse meio tem sido estudado por vários autores que comprovam sua eficácia no isolamento de salmonelas (Neter e Clark, ${ }^{8}$ Costa e col. ${ }^{3}$ ); tem-se, entretanto, mostrado inibidor para algumas amostras de salmonelas (Banwart e Ayres ${ }^{1}$; Taylor e col.10; Braide e col.2). Para o isolamento do maior número possivel de salmonelas, segundo Edwards e Ewing ${ }^{5}$, indica-se 0 meio Agar Verde Brilhante e para isolamento de $S$. typhi o melhor é o meio Agar Sulfito de Bismuto. Segundo Taylor ${ }^{9}$, os meios de cultura usados no isolamento de germes entéricos patogênicos, apresentam duas deficiências fundamentais: falsos resultados positivos e inibição dos patogênicos mais delicados. Esse autor idealizou um meio de cultura procurando eliminar essas falhas. E o meio de xilose-lisina, que tem três variações: a) Agar Base Xilose Lisina, que é um meio não inibitório indicado para o estudo quantitativo de bactérias entericas; b) Agar Xilose Lisina Desoxicolato que utiliza o desoxicolato como inibidor e é indicado para o isolamento de shigelas e outros patogênicos no laboratório clínico; c) Agar Xilose Lisina Verde Brilhante que utiliza o corante como inibidor e é indicado para a pesquisa de salmonelas no laboratório de alimentos. As três variações diferem apenas em relação ao elemento inibidor e têm como mecanismo o seguinte: o empregu de um carboidrato (xilose), que não é fermentado pelas shigelas ou o é muito lentamente. Como esse açúcar é fermentado pelas salmonelas, adiciona-se lisina, que é descarboxilada pelas salmonelas revertendo a $\mathrm{um} \mathrm{pH}$ alcalino, lembrando assim a reação de shigela. Para que os coliformes lisina positivos não possam também reverter, adiciona-se lactose e sacarose em excesso, produzindo um máximo de acidez impedindo, desse modo, a reversão. Como ajuda adiciona-se um indicador de $\mathrm{H}_{2} \mathrm{~S}$ para evidência rápida de salmonela. Como os proteus não descarboxilam lisina, a acidez previne o enegrecimento de suas colônias até que a cultura seja interpretada, o que deve ser feito entre 18 e 24 horas e nunca depois desse tempo.

O objetivo da presente pesquisa é realizar uma avaliação do meio Agar Xilose Lisina Verde Brilhante para o isolamento de Salmonella, não só de alimentos mas também de fezes, quer de animais quer do homem, comparando-o a outros meios de cultura normalmente usados para o isolamento desses microrganismos.

\section{MATERIAL E METODOS}

Material examinado - a) alimentos correspondente a 25 amostras de carne moída e a 25 amostras de fígado de porco, boi e galinha, adquiridos em açougues e supermercados, nas condições em que eram entregues ao consumidor; b) fezes humanas - correspondente a 47 amostras, colhidas de crianças com manifestações de gastroenterite; c) fezes de animais correspondente a 51 amostras de diferentes animais quer domésticos, quer de zoológico.

Meios de isolamento - Além do Agar Xiluse Lisina Verde Brilhante (Agar XLVB), foram avaliados os seguintes meios de cultura: Agar Eosina Azul de Metileno (Agar EMB), Agar SS, Agar Verde Brilhante e Agar Sulfito de Bismuto, todos da marca Difco. O meio Agar Xilose Lisina Verde Brilhante foi preparado no laboratório segundo a indicação de Taylor 9.

Técrica de Execuçūo - Todas as amostras de fezes eram adicionadas à solução conservadora de Teague e Clurman modificada (Edwards e Ewing 5 ), e nos meios de enriquecimento "Tetrationath Broth Base" Difco, adicionado de solıçāo de verde brilhante a $0,1 \%$ e meio de Rappaport modificado (Falcão e Suassuna ${ }^{\circ}$ ). 
F'ALCAO, D. P. et al. Avaliação do meio "Agar Xilose Lisina Verde Brilhante" no 1solamento de Salmonella. Rev. Saúde puibl., S. Paulo, 13:43-6, 1979.

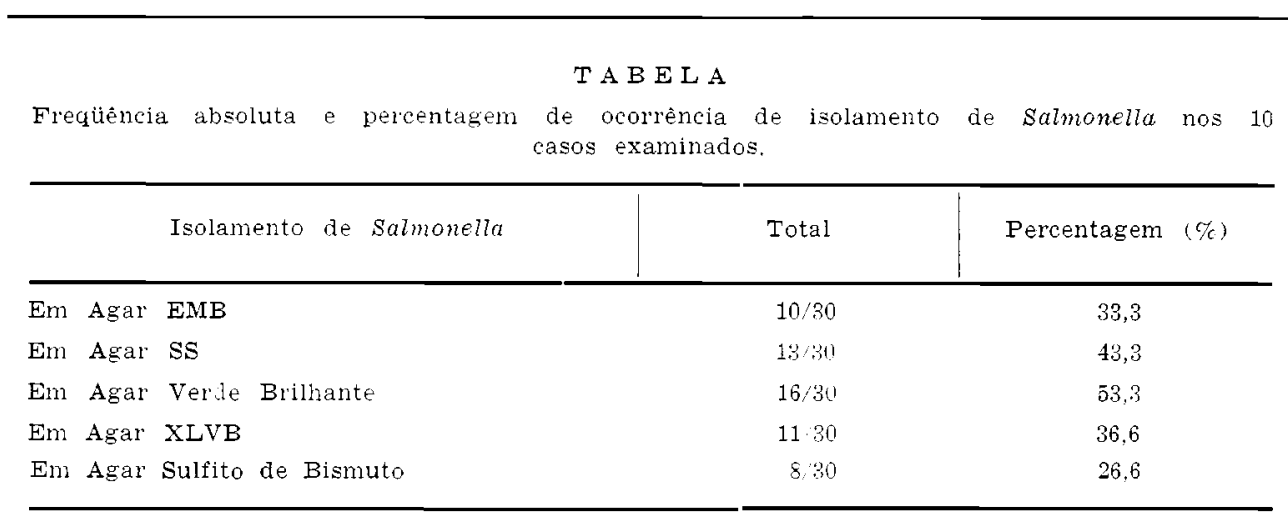

A partir da solução conservadura o material foi imediatamente semeado nos meios de isolamento; os meios de enriquecimento foram incubados a $35-37^{\circ} \mathrm{C}$ durante $24 \mathrm{~h}$, antes de serem igualmente semeados nos meios de isolamento.

As amostras de alimentos eram previamente trituradas assepticamente com salina na proporção de $10 \%$. A mistura era deixada sedimentar por alguns minutos; a partir do sobrenadante procedia-se como para os espécimes de fezes. Utilizou-se, portanto, três placas de cada meio de isolamento para cada material examinado.

As colônias suspeitas de serem de Salmonella foram confirmadas bioquímica e sorologicamente (Edwards e Ewing ${ }^{5}$ ).

\section{RESULTADOS}

Foram isoladas salmonelas a partir de 10 materiais examinados, sendo que em sete deles isolou-se $S$. anatum, em dois $S$. derby, e em um S. daytona.

São apresentadas na Tabela a freqüência absoluta e a percentagem de ocorrência de isolamento de Salmonella nos 10 casos positivos pelas três placas de cada meio de cultura.

\section{DISCUSSÃO}

Segundo Taylor', o meio Agar Xilose Lisina Verde Brilhante combina maior grau de diferenciação que o encontrado nos meios Agar EMB, ou Agar MacConkey, com maior grau de sensibilidade para as bactérias entéricas fastidiosas, que os meios Agar SS, Agar Verde Brilhante e Agar Sulfito de Bismuto. Através de dados de nosso trabalho, observamos resultados diferentes. Assim obtivemos percentagem de isolamento inferior à fornecida pelos meios Agar SS e Agar Verde Brilhante e ligeiramente superior à apresentada pelo meio Agar EMB; só o meio de Agar Sulfito de Bismuto é que apresentou resultados mais limitados.

Observamos, entretanto, que o meio Agar Xilose Lisina Verde Brilhante apresenta uma grande vantagem, - as colônias de Salmonella apresentam-se facilmente identificáveis e em grande número numa mesma placa. Julgamos, pois ser este um meio que deve constar, ao lado de outros, no isolamento desses germes. 
FALCAO, D. P. et al. Avaliação do meio "Agar Xilose Lisina Verde Brilhante" no isolamento de Salmonella. Rev. Saude puibl., S. Paulo, 13:43-6, 1979.

Falcão, D. P. et al. TThe evaluation of Xylose Lysine Brilliant Green Agar medium in the isolation of Salmonella.j Rev. Saúde públ., S. Palllo, 13: $43-6,1979$.

ABSTRACT: For the isolation of Salmonella from a variety of sources many. different culture media were used. One of them, the Xylose Lysine Brilliant Green Agar medium, was employed to evaluate it in relation to the other selective-indicator media most commonly used in the isolation of these microorganisms. The results showed that X ylose Lysine Brilliant Green Agar was inferior to SS Agar and Brilliant Green Agar, slightly superior to EMB Agar. and superior to Bismuth Sulfite Agar for the isolation of Salmonella. Its great advantage is that it permits easy' identification of the Salmonella colonies.

UNITERMS: Salmonella, isolation. Culture media.

\section{REFERENCIAS BIBLIOGRÁEICAS}

1. BANWART, G. J. \& AYRES. J. C. Effects of various enrichement broths and selective Agars upon the growth of several species of Salmonella. Appl. Microbiol., 1:296-301. 1953.

2. BRAIDE, M. A. et al. Imbição do cresc1mento de Salmonella e shigella em Agar SS. Ciênc. Cult., 19:421, 1967.

3. COSTA, G. A, et al. Comparação de meios seletivo-indicadores e de enriquecimento usados no isolamento de enterobactérias patogênicas. An. Microbrol., Rio de Janeiro, 5:239-304, 1957.

4. DIFCo, Manual. 9a ed. Detroit. Difeo Laboratories, 1964.

5. EDWARDS, P. R. \& EWING. W. H. Identifications of Enterobacteriaceae $3 \mathrm{~m}$ ed. Minneapolis, Burgess Publishing. 1972.

6. FALCão, D. P. \& SUASSUNA, I. Comparação do meio de Rappaport e do meio de Tetrationato de Kauffmann, en diversos esquemas para isolamento de Salmonella. Isolamento eventual de Shigella. Rev. Microbiol., 2:29-36. 1971.

7. LEVINE, M. \& TANIMOTO, R. H. Antagonisms among enteric pathogens and coliform bacteria. J. Bact., 67:537-41. 1954.

8. NETER, E. R. \& CLARK, P. The effectiveness of different culture media in the isolation of enteric microrganism. Amer. J. dig. Dis., 11:229-33, 1944.

9. TAYLOR, W. I. Isolation of Shigella I Xylose Lysine agars: new media for isolation of enteric pathogens. Rev. med. Technol., 35:471-5, 1965.

10. TAYLOR. W. I. et al. Isolation of Salmonellae from food samples. 1 - Factors affecting the choise of media for the detection and enumeration of Salmonella. Appl. Miorobiol, 6:189-93. 1958.

Recebıdo para publicação em 22/09, 1978 Aprovado para publicacão em $09 / 11: 1978$ 